\title{
Foregut Cyst Case Report
}

\author{
Sushanta* \\ Consultant \& Head-Department of Emergency Medicine, Emergency Medicine, Manipal Hospital, India
}

*Corresponding author: Sushanta, Consultant \& Head-Department of Emergency Medicine, Emergency Medicine, Manipal Hospital, India

\begin{abstract}
A 70-year-old female presented with gradual onset dyspnea with moderate exertion for 6 months. She had history of stroke 1 month back which was resolved. On 2D echo she had a mass in LA $(1.6 \times 1.6 \mathrm{~cm})$ with base

attached to IAS adjacent to AML. On coronary angiography she had lesion in LAD with $60-70 \%$ stenosis. But intraoperative TEE revealed mass in left ventricle attached to PML undersurface. The operation was performed, CABG with LIMA to LAD grafting \& transannular decompression of the LV mass performed. Surgery done uneventfully. The cyst content consists of necrotic sebaceoustype material with calcification. Histopathology of excised material revealed it to be a foregut cyst of myocardium. The patient had an uneventful postoperative course and was discharged in good clinical condition.
\end{abstract}

Keywords: Foregut cyst; Left ventricle; Transannular decompression

\section{Introduction}

Foregut cysts have been described in a variety of locations in the mediastinum. They arise from embryonic remnants of the primitive foregut and include bronchogenic cysts arising from the ventral foregut and enterogenous cysts arising from the dorsal foregut. The foregut cyst, which is a general term encompasses bronchogenic, esophageal, gastric, or enteric cysts. Intracardiac foregut cysts can be diagnosed with transthoracic echocardiography as a spaceoccupying lesion with compressive effects; hence, the reduction in cardiac function or blood flow obstruction. The majority of these cysts are managed with early surgical resection [1] to obtain tissue diagnosis and [2] to prevent complications related to their enlargement.

\section{Case Report}

A 70 yrs old female presented with $\mathrm{c} / \mathrm{c}$ of dyspnea with moderate exertion for 6 months. She has history of stroke 1 month back which was resolved with no neurologic deficit at present. She is $\mathrm{k} / \mathrm{c} / \mathrm{o}$ T2 diabetes mellitus. She was evaluated in our hospital. All blood investigations are WNL. Coronary angiography showed single vessel disease of LAD with 60-70\% stenosis. On carotid doppler she has B/L carotid disease (30-40\% stenosis). But MR angiography neck vessels show normal course \& caliber. MRI brain showed subacute chronic infarct in right fronto-tempo parietal region.

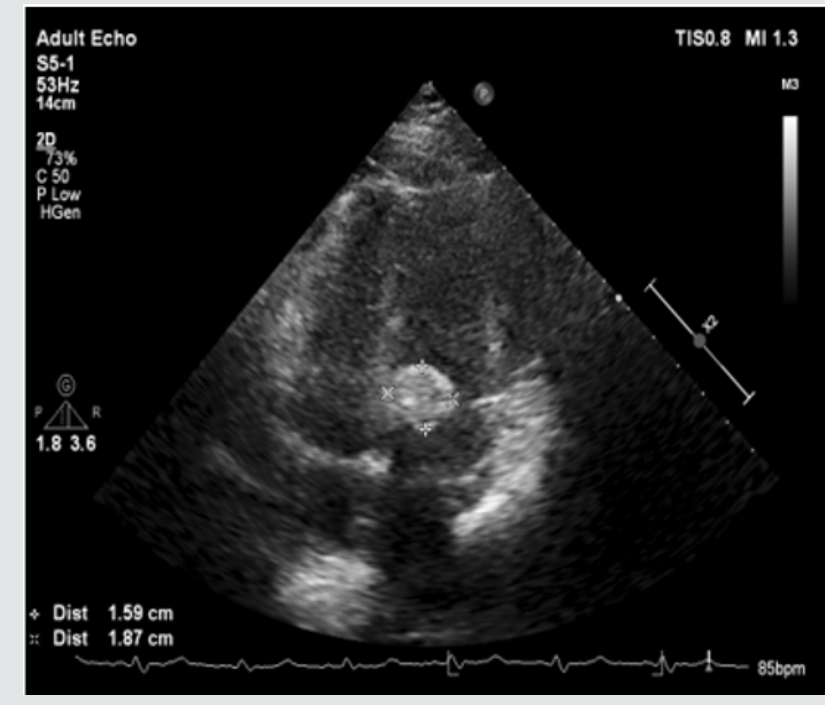

Figure 1: 2D Echo Apical 4C view.

On 2D Echo revealed EF of $60 \%$. Moderate LVH. Aortic leaflets are thickened \& calcific. MIP grade 1 . There is a mass in left atrium $(1.6 \times 1.6 \mathrm{~cm})$ with its base attached to interatrial septum adjacent to AML base. LA myxoma? Trace MR, MAC present. Pt was planned for CABG + LA myxoma removal. Interperative we did TEE to confirm diagnosis \& to locate and measure size of mass. We found 
the mass in left ventricle which was attached to base of posterior mitral leaflet. Mass seen likely to be a cystic mass (Figures 1-3). An attempt to take a biopsy sample of the mass resulted in extrusion of the cyst contents, which consisted of necrotic material that had a pasty yellowish-gray appearance. The contents were evacuated, and the cyst wall closed from within the left ventricle. There was no plane of dissection that would allow removal of the cyst. After completion of the coronary bypass grafting \& decompression of cyst, the heart separated from cardiopulmonary bypass satisfactorily. Histopathological study of the excised material revealed it to be Foregut cyst of myocardium.

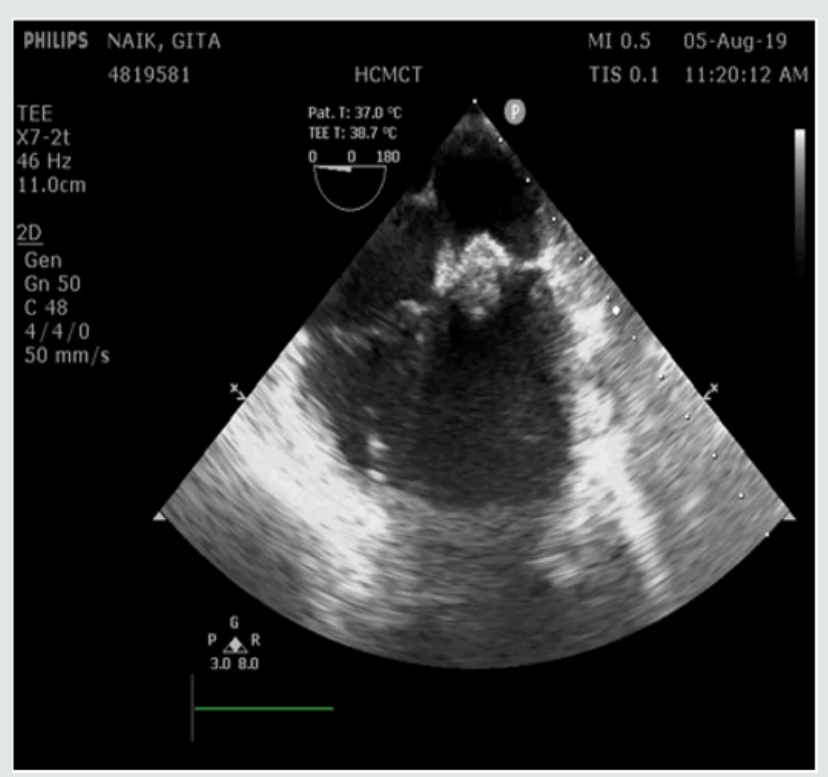

Figure 2: TEE view Midoesophageal 4C view showing a mass underneath the mitral valve.

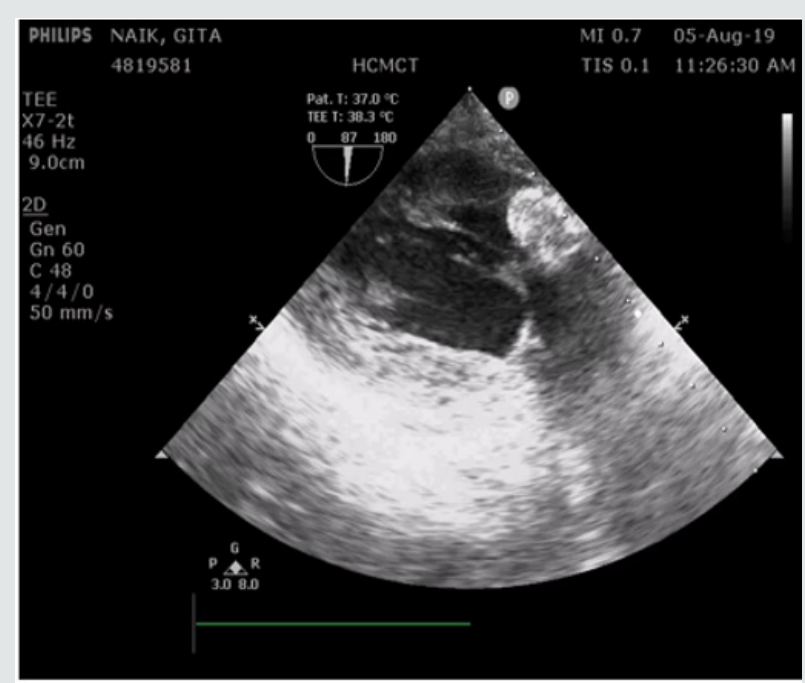

Figure 3: TEE- transgastric $2 \mathrm{C}$ view showing a mass under the Posterior mitral leaflet.

\section{Comment}

Cysts of the myocardium are very uncommon. When they occur, they are most commonly hydatid cysts. Myocardial involvement occurs in less than $2 \%$ of hydatid disease [1]. Hydatid cysts in the heart usually shell out from the surrounding myocardium relatively easily. Although a positive histologic diagnosis could not be made in either of these cases, the findings are typical of degenerate foregut cysts. In this case, the cyst wall was fibrous and calcified with no epithelial lining identified. The cyst contained necrotic sebaceoustype material with calcification typical of foregut cysts [2]. Foregut cysts more commonly occur in the mediastinum where the natural history is one of enlargement and compression of surrounding structures due to infection, epithelial secretions, or bleeding. Two thirds of patients eventually develop symptoms due to airway obstruction.

In a series of 444 adult autopsies with a primary tumor or cyst of the heart or pericardium, 6 patients had an intramyocardial bronchogenic cyst [3]. These were the only intramyocardial cysts; they were 1 to $2 \mathrm{~cm}$ in diameter and were incidental findings. One of the six cysts crossed the posterior atrioventricular groove as in our patient. In the same series, there were 80 simple pericardial cysts and 118 myxomas. Shelling out of these rare foregut cysts may not be possible because the cyst wall may degenerate to a thin, fibrous capsule intimate with the adjacent myocardium. The size of the cyst may also preclude cyst removal due to disruption of ventricular or valve function, depending on the location. In this circumstance, decompression by drainage may be the most judicious management.

Intracardiac foregut cysts can be diagnosed with transthoracic echocardiography as a space-occupying lesion with compressive effects; hence, the reduction in cardiac function or blood flow obstruction. Diagnosis is by histopathology, in which, we see endodermal and mesodermal elements. Teratomas are the main differential diagnosis of foregut cysts, in which, we see ectodermal elements too [4]. Because these cysts are rare, there is an inclination to obtain a tissue diagnosis at the time of cardiac surgery. There is a reluctance to leave the cyst cavity communicating with a cardiac chamber, and so it is recommended that the cysts be drained into the pericardium. Aggressive evacuation of the contents does not appear necessary and may cause bleeding from the cyst wall. The presence of radiopaque material within the cyst should distinguish it from other types of cysts so that it is reasonable to make a positive diagnosis without tissue confirmation.

\section{References}

1. Miralles A, Bracamonte L, Pavie L, Bors V, Rabago G et al. (1994) Cardiac echinococcosis. Surgical treatment and results. J Thorac Cardiovasc Surg 107(1): 184-90.

2. Strollo D, Rosado de Christenson ML, Jett JR (1997) Primary mediastinal tumors: part II. Tumors of the middle and posterior mediastinum. Chest 112(5): 1344-1357.

3. Mc Allister HA, Fenoglio JJ (1978) Tumors of the cardiovascular system. In: Hartman WH, Cowan WR, (eds.) Atlas of tumor pathology. Fascicle 15, second series. Armed Forces Institute of Pathology, Washington, DC, USA, p. 1-64.

4. Huang JH, Rudzinski ER, Minette MS, Langley SM (2013) First case of intracardiac foregut cyst occurring in the left-ventricular outflow tract. Pediatr Cardiol 34(8): 2060-2062. 
(c) This work is licensed under Creative

To Submit Your Article Click Here: Submit Article

DOI: $10.32474 /$ GJAPM.2020.02.000140

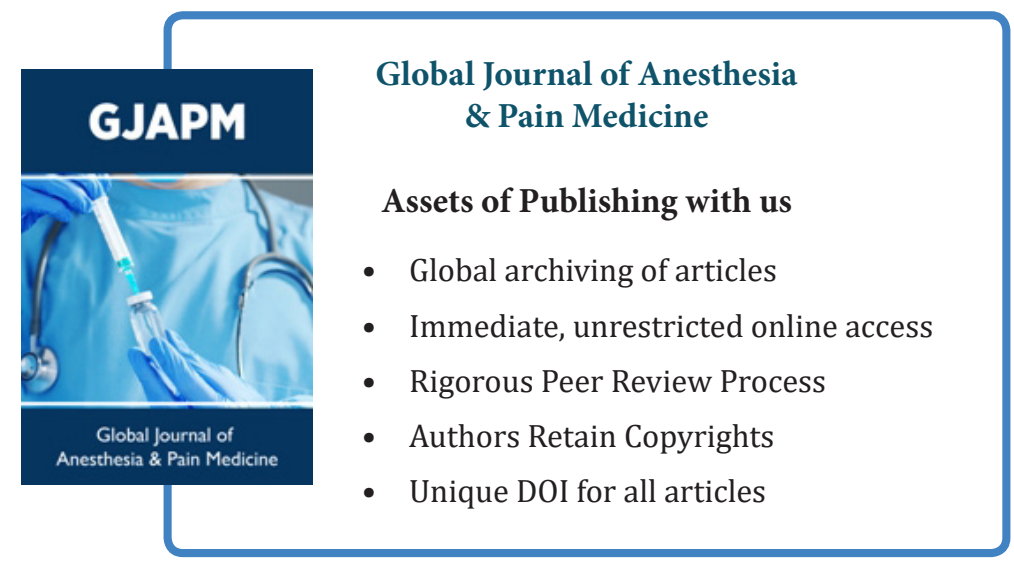

